\title{
Performance Evaluation of Small-Medium Enterprises Based on Management and Organization
}

\author{
M. Cengiz Toklu* And H. TaşKin \\ Sakarya University, Industrial Engineering Department, Sakarya, Turkey
}

\begin{abstract}
Companies need to constantly evaluate their activities in strategic planning process. These activities include all processes in the company, such as management and organization, research and development, production planning, manufacturing, post-sales services, accounting and finance. The aim of this study is to propose an evaluation model that can be used to evaluate management and organization performance for small and medium enterprises. In the proposed model, fuzzy multi-criteria decision-making approaches consisting of fuzzy analytic network process and fuzzy decision making trial and evaluation laboratory methods are used to determine the weights of performance criteria. A case study has been conducted in a small and medium enterprise for empirical evidence. From the outcome of our investigation, it is possible to conclude that "corporate communication" and "process management" are more important criteria. The most important sub-criteria are listed as, "senior management in harmony with each other", "employee requests and demands are collected periodically" and "pocket reference that includes procedures and fixed rules are available".
\end{abstract}

DOI: 10.12693/APhysPolA.132.994

PACS/topics: 89.65.Gh, 07.05.Mh

\section{Introduction}

Small and medium enterprises (SMEs) have a growing and crucial role in both developed and developing countries. Particularly, the manufacturing industry rises in importance in these countries. In today's world, manufacturing SMEs face innumerable challenges on there way to prosperity. These enterprises often either do not have an adequate understanding of, or access to, the resources, technologies, and management practices needed to meet these challenges [1].

Despite their limited resources, manufacturing SMEs require sustainability-related tools with systematic guidance, manageable complexity and a reasonable timeframe [2]. In situations such as this, performance measurement or evaluation models can be used as a solution tool. Performance measurement is an important issue for management and it is mainly used for monitoring existing performance, identifying the gap between expected and existing performance, identifying performance improvement opportunities and supporting continuous improvement, providing information for long-term decisions and enabling interaction between processes and stakeholders [3]. The aim of this study is to propose a flexible, dynamic and practical performance evaluation tool from management and organization viewpoint for SMEs.

Traditional performance measurement models focus on financial criteria [4]. To minimize weaknesses of traditional performance measurement system, several models have been developed such as Performance Pyramid, European Foundation for Quality Management Excellence Model, Balance Score Card, Performance Measurement

*corresponding author; e-mail: mtoklu@sakarya.edu.tr
Matrix, Performance Measurement Questionnaire, Strategic Measurement and Reporting Technique and Malcolm Baldrige National Quality Award. In general, these models have been developed to be applied in big companies. When the literature was searched to have a general idea, there was a limited number of studies related to performance evaluation system for SMEs. From this point of view, the proposed model is developed considering the limited resources of SMEs and their own criteria.

The model is developed by also taking into consideration the weaknesses of models in literature, such as lack of different points of view, not allowing specific criteria within the company, requirement of a lot of resource, time and money. There are several studies about performance measurement and evaluation in the literature. Related studies can be classified into three categories; (a) studies about performance evaluation of SMEs (b) performance evaluation with multi-criteria decision making (MCDM) methods and (c) performance evaluation with hybrid use of decision making trial and evaluation laboratory (DEMATEL) and analytic hierarchy process/analytic network process (AHP/ANP) methods. In addition to these, MCDM methods have been used in different problems that require evaluation, selection, sorting and classification in the literature [5-12]. Table I shows studies in the literature, related to these three main categories.

TABLE I

Studies related to three main categories of evaluation of SMEs.

\begin{tabular}{c|c}
\hline \hline Performance evaluation studies & Refs. \\
\hline Performance evaluation studies for SMEs & {$[13-20]$} \\
Performance evaluation with MCDM & {$[21-27]$} \\
Performance evaluation with DEMATEL & {$[28-29]$} \\
and AHP/ANP &
\end{tabular}


However, to the best knowledge of the authors, not enough studies have been conducted on the subject of performance evaluation in SMEs, based on management and organization with fuzzy MCDM methods.

\section{Proposed model}

Performance evaluation is a MCDM problem and it is affected by quantitative and qualitative factors [30]. For this reason, proposed model is developed based on MCDM approaches and includes four main steps. The first step is the determination of the criteria set. Criteria set are derived from the literature and case study. Different companies can add their own special criteria or they can reduce the criteria set. This flexibility allows the model to be implemented in different industries. The second step is about the examination of interactions among performance criteria with F-DEMATEL method. The third step is prioritization of criteria by using the F-ANP method. Finally, performance evaluation is realized and action plans are created (Fig. 1).

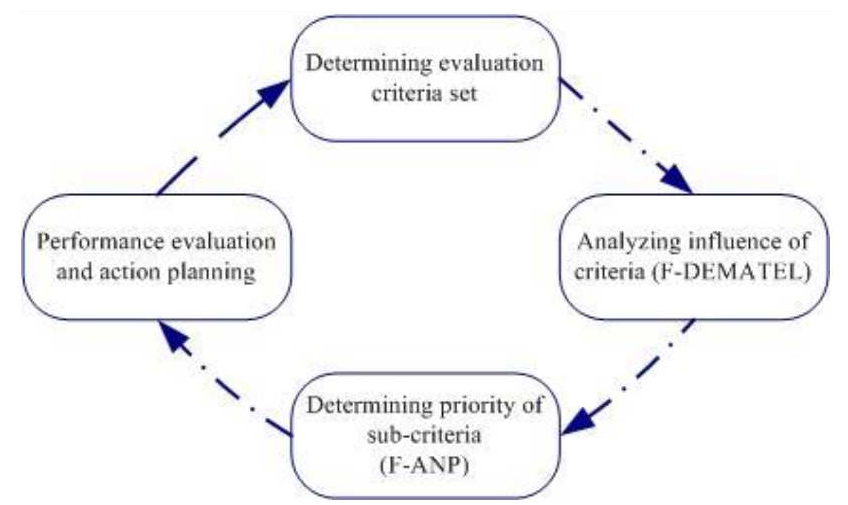

Fig. 1. Steps of proposed model.

\section{Methodology}

The fuzzy set theory was described in the work of Zadeh [31]. There are different techniques in the literature that benefit from fuzzy set theory. One of the important elements of the fuzzy set theory is a linguistic variable which adopts natural language expressions as its value [32]. In this study performance criteria are sorted in descending order in an attempt to make strategic decisions. For this purpose, F-DEMATEL is used to examine the causal relationships among performance criteria and F-ANP is used to determine weights of performance criteria.

\subsection{Fuzzy DEMATEL method}

The DEMATEL method was employed by Fontela and Gabus [33-36] between 1972 and 1976 to solve complex problems. The Fuzzy DEMATEL method is developed for analyzing the influence of criteria in fuzzy environments by Lin and Wu [37]. Table II shows the linguistic terms and corresponding triangular fuzzy numbers (TFNs).
TABLE II

The linguistic terms and TFNs.

\begin{tabular}{c|c}
\hline \hline Linguistic terms & TFNs \\
\hline No influence & $(0,0,0.25)$ \\
Very low influence & $(0,0.25,0.50)$ \\
Low influence & $(0.25,0.50,0.75)$ \\
High influence & $(0.50,0.75,1.0)$ \\
Very high influence & $(0.75,1.0,1.0)$
\end{tabular}

The major steps of the F-DEMATEL [37] are explained as follows;

Obtaining the assessments of all decision-makers;

$$
\tilde{Z}=\frac{\tilde{Z}_{1}+\tilde{Z}_{2}+\ldots+\tilde{Z}_{p}}{p},
$$

where $\tilde{Z}$ is initial direct relation fuzzy matrix.

$$
\tilde{Z}=\left[\begin{array}{cccc}
0 & \tilde{z}_{12} & \cdots & \tilde{z}_{1 n} \\
\tilde{z}_{21} & 0 & \cdots & \tilde{z}_{2 n} \\
\vdots & \vdots & \ddots & \vdots \\
\tilde{z}_{n 1} & \tilde{z}_{n 2} & \cdots & 0
\end{array}\right]
$$

Normalized direct-relation fuzzy matrix;

$$
\tilde{X}=\left[\begin{array}{cccc}
\tilde{x}_{11} & \tilde{x}_{12} & \cdots & \tilde{x}_{1 n} \\
\tilde{x}_{21} & \tilde{x}_{22} & \cdots & \tilde{x}_{2 n} \\
\vdots & \vdots & \ddots & \vdots \\
\tilde{x}_{n 1} & \tilde{x}_{n 2} & \cdots & \tilde{x}_{n n}
\end{array}\right]
$$

where

$$
\begin{aligned}
& \tilde{x}_{i j}=\frac{\tilde{z}_{i j}}{r}=\left(\frac{l_{i j}}{r}, \frac{m_{i j}}{r}, \frac{u_{i j}}{r}\right), \\
& r=\max _{1 \leq i \leq n}\left(\sum_{j=1}^{n} u_{i j}\right) .
\end{aligned}
$$

Total-relation fuzzy matrix $(\tilde{T})$;

$$
\begin{aligned}
& X_{l}=\left[\begin{array}{cccc}
0 & l_{12}^{\prime} & \cdots & l_{1 n}^{\prime} \\
l_{21}^{\prime} & 0 & \cdots & l_{2 n}^{\prime} \\
\vdots & \vdots & \ddots & \vdots \\
l_{n 1}^{\prime} & l_{n 2}^{\prime} & \cdots & 0
\end{array}\right] \\
& X_{m}=\left[\begin{array}{cccc}
0 & m_{12}^{\prime} & \cdots & m_{1 n}^{\prime} \\
m_{21}^{\prime} & 0 & \cdots & m_{2 n}^{\prime} \\
\vdots & \vdots & \ddots & \vdots \\
m_{n 1}^{\prime} & m_{n 2}^{\prime} & \cdots & 0
\end{array}\right] \\
& X_{u}=\left[\begin{array}{cccc}
0 & u_{12}^{\prime} & \cdots & u_{1 n}^{\prime} \\
u_{21}^{\prime} & 0 & \cdots & u_{2 n}^{\prime} \\
\vdots & \vdots & \ddots & \vdots \\
u_{n 1}^{\prime} & u_{n 2}^{\prime} & \cdots & 0
\end{array}\right]
\end{aligned}
$$




$$
\tilde{T}=\left[\begin{array}{cccc}
\tilde{t}_{11} & \tilde{t}_{12} & \cdots & \tilde{t}_{1 n} \\
\tilde{t}_{21} & \tilde{t}_{22} & \cdots & \tilde{t}_{2 n} \\
\vdots & \vdots & \ddots & \vdots \\
\tilde{t}_{n 1} & \tilde{t}_{n 2} & \cdots & \tilde{t}_{n n}
\end{array}\right],
$$

where

$$
\begin{aligned}
& \tilde{t}_{i j}=\left(l_{i j}^{\prime \prime}, m_{i j}^{\prime \prime}, u_{i j}^{\prime \prime}\right) . \\
& {\left[l_{i j}^{\prime \prime}\right]=X_{l} \times\left(I-X_{l}\right)^{-1},} \\
& {\left[m_{i j}^{\prime \prime}\right]=X_{m} \times\left(I-X_{m}\right)^{-1},} \\
& {\left[u_{i j}^{\prime \prime}\right]=X_{u} \times\left(I-X_{u}\right)^{-1} \cdot} \\
& \tilde{T}^{\text {def }}=\left[\begin{array}{cccc}
\tilde{t}_{11}^{\text {def }} & \tilde{t}_{12}^{\text {def }} & \ldots & \tilde{t}_{1 n}^{\text {def }} \\
\tilde{t}_{21}^{\text {def }} & \tilde{t}_{22}^{\text {def }} & \ldots & \tilde{t}_{2 n}^{\text {def }} \\
\vdots & \vdots & \ddots & \vdots \\
\tilde{t}_{n 1}^{\text {def }} & \tilde{t}_{n 2}^{\text {def }} & \cdots & \tilde{t}_{n n}^{\text {def }}
\end{array}\right],
\end{aligned}
$$

where

$$
\tilde{t}_{i j}^{\text {def }}=\left(l_{i j}^{\prime \prime}, m_{i j}^{\prime \prime}, u_{i j}^{\prime \prime}\right)^{\text {def }} .
$$

Total-relation fuzzy matrix includes fuzzy values. For this reason a defuzzification process is needed. Even though several defuzzification methods exist in literature, converting fuzzy data into crisp scores (CFCS) method $[38]$ is used for defuzzification process.

\subsection{Fuzzy ANP method}

ANP method is developed by Saaty [39] to eliminate the problem of interrelation among criteria. There are several F-ANP methods for calculating weights. In this study, Chang's extent analysis method [40] is used. The linguistic terms and their corresponding TFNs are shown in Table III.

TABLE III

The linguistic terms and TFNs.

\begin{tabular}{c|c|c}
\hline \hline Linguistic terms & TFNs & $\begin{array}{c}\text { Triangular fuzzy } \\
\text { reciprocal numbers }\end{array}$ \\
\hline Equally important & $(1,1,1)$ & $(1,1,1)$ \\
Weekly important & $(1,3,5)$ & $(1 / 5,1 / 3,1)$ \\
Strongly important & $(3,5,7)$ & $(1 / 7,1 / 5,1 / 3)$ \\
Very important & $(5,7,9)$ & $(1 / 9,1 / 7,1 / 5)$ \\
Absolutely important & $(7,9,9)$ & $(1 / 9,1 / 9,1 / 7)$
\end{tabular}

Chang's method [40] is described below.

Let $X=\left\{x_{1}, x_{2}, \ldots, x_{n}\right\}$ be an object set, and $G=$ $\left\{g_{1}, g_{2}, \ldots, g_{m}\right\}$ be a goal set.

$M_{g_{i}}^{j}(i=1,2, \ldots, n ; j=1,2, \ldots, m)$ are TFNs.

$$
\begin{aligned}
& S_{i}=\sum_{j}^{m} M_{g_{i}}^{j} \otimes\left[\sum_{i=1}^{n} \sum_{j=1}^{m} M_{g_{i}}^{j}\right]^{-1}, \\
& \sum_{j}^{m} M_{g_{i}}^{j}=\left(\sum_{j=1}^{m} l_{j}, \sum_{j=1}^{m} m_{j}, \sum_{j=1}^{m} u_{j}\right), \\
& \sum_{i=1}^{n} \sum_{j=1}^{m} M_{g_{i}}^{j}=\left(\sum_{i=1}^{n} l_{i}, \sum_{i=1}^{n} m_{i}, \sum_{i=1}^{n} u_{i}\right), \\
& {\left[\sum_{i=1}^{n} \sum_{j=1}^{m} M_{g_{i}}^{j}\right]^{-1}=\left(\frac{1}{\sum_{i=1}^{n} u_{i}}, \frac{1}{\sum_{i=1}^{n} m_{i}}, \frac{1}{\sum_{i=1}^{n} l_{i}}\right) .}
\end{aligned}
$$

$M_{2}=\left(l_{2}, m_{2}, u_{2}\right) \geq M_{1}=\left(l_{1}, m_{1}, u_{1}\right)$ is defined as $V\left(M_{2} \geq M_{1}\right)=\sup \left[\min \left(\mu_{M_{1}}(x), \mu_{M_{2}}(y)\right)\right]$.

$$
\begin{gathered}
V\left(M_{2} \geq M_{1}\right)=\operatorname{hgt}\left(M_{1} \bigcap M_{2}\right)=\mu_{M_{2}}(d) \\
\quad=\left\{\begin{array}{cl}
1, & \text { if } m_{2} \geq m_{1}, \\
0, & \text { if } l_{1} \geq u_{2}, \\
\frac{l_{1}-u_{2}}{\left(m_{2}-u_{2}\right)-\left(m_{1}-l_{1}\right)}, & \text { otherwise, }
\end{array}\right.
\end{gathered}
$$

where $d$ is the ordinate of the highest intersection point $d$ between $\mu_{M_{1}}$ and $\mu_{M_{2}}$. Both values of $V\left(M_{1} \geq M_{2}\right)$ and $V\left(M_{2} \geq M_{1}\right)$ are required in order to compare $M_{1}$ and $M_{2}$.

$$
\begin{aligned}
& V\left(M \geq M_{1}, M_{2}, \ldots, M_{k}\right)=V\left[\left(M \geq M_{1}\right)\right. \text { and } \\
& \left.\quad\left(M \geq M_{2}\right) \text { and } \ldots \text { and }\left(M \geq M_{k}\right)\right] \\
& \quad=\min V\left(M \geq M_{i}\right), \quad i=1,2, \ldots, k . \\
& \text { Assume that } \\
& d^{\prime}\left(A_{i}\right)=\min V\left(S_{i} \geq S_{k}\right),
\end{aligned}
$$

for $k=1,2, \ldots, n ; k \neq i$.

$$
W^{\prime}=\left(d^{\prime}\left(A_{1}\right), d^{\prime}\left(A_{2}\right), \ldots, d^{\prime}\left(A_{n}\right)\right)^{T},
$$

where $A_{i}(i=1,2, \ldots, n)$ are $n$ elements.

$$
W=\left(d\left(A_{1}\right), d\left(A_{2}\right), \ldots, d\left(A_{n}\right)\right)^{T},
$$

where $W$ is a non-fuzzy number.

\section{Case study}

Proposed model was applied in a manufacturing SME. The company is examined on the basis of organization and management department. Evaluation criteria are structured around five main criteria. These are (C1) leadership, (C2) process management, (C3) strategic management, (C4) corporate communication and (C5) information and technology management. Each criterion has its own sub-criteria and there are 18 sub-criteria in total (Table IV). 
TABLE IV

Evaluation criteria of management and organization.

\begin{tabular}{|c|c|c|}
\hline Criteria & Ref. & Sub-criteria \\
\hline C1. Leadership & $\begin{array}{l}{[41,42]} \\
{[18,15]} \\
{[43]}\end{array}$ & $\begin{array}{l}\text { C11. Existing leaders who shape the future } \\
\text { C12. Senior executives are evaluated periodically by employees } \\
\text { C13. There is a corporate culture sustained by leaders and employees } \\
\text { C14. The company has a strong relationship with the local community }\end{array}$ \\
\hline $\begin{array}{l}\text { C2.Process } \\
\text { management }\end{array}$ & $\begin{array}{l}{[18,41,44]} \\
{[18,42]}\end{array}$ & $\begin{array}{l}\text { C21. Departmentalization is completed and departments operate in a synchronized manner } \\
\text { C22. Core processes and process components (owners, inputs, outputs, etc.) are declared } \\
\text { C23. Organizational chart and job descriptions are determined and updated } \\
\text { C24. Pocket reference that includes procedures and fixed rules are available }\end{array}$ \\
\hline $\begin{array}{l}\text { C3. Strategic } \\
\text { management }\end{array}$ & $\begin{array}{l}{[15,4143]} \\
{[15,18]} \\
{[15,18]} \\
{[41]}\end{array}$ & $\begin{array}{l}\text { C31. Organizational mission, vision and values are defined and a formal strategic planning } \\
\text { process is available in order to realize its mission and vision } \\
\text { C32. Self-assessment activity are conducted periodically within the scope of corporate } \\
\text { evaluation } \\
\text { C33. Budget planning and resource allocation are performed } \\
\text { C34. Sustainability approach is incorporated into all business processes and strategy }\end{array}$ \\
\hline $\begin{array}{l}\text { C4. Corporate } \\
\text { communication }\end{array}$ & $\begin{array}{l}{[43]} \\
{[42,45]}\end{array}$ & $\begin{array}{l}\text { C41. Senior management are in harmony with each other } \\
\text { C42. Employees at different departments and levels have same achievement motive } \\
\text { C43. Employee requests and demands are collected periodically }\end{array}$ \\
\hline $\begin{array}{l}\text { C5. Information } \\
\text { and technology } \\
\text { management }\end{array}$ & $\begin{array}{l}{[18,42]} \\
{[18]} \\
{[18]}\end{array}$ & $\begin{array}{l}\text { C51. Data are transformed into real information to make the right decision and stored as } \\
\text { enterprise information } \\
\text { C52. Regular meetings are held in an effort of decision making, planning and problem solving } \\
\text { C53. New technologies are being followed and technology investments are being planned }\end{array}$ \\
\hline
\end{tabular}

Interactions between main criteria are calculated with F-DEMATEL upon expert opinions. In the F-DEMATEL method a threshold value is needed to interpret the relationship. Table $\mathrm{V}$ shows values which are above the predefined threshold (0.680). The threshold value has been determined according to the opinions of the experts from the company. For instance, C1 affects C3 (0.682) and C4 (0.747), likewise C2 affects C3 (0.713), C4 (0.783) and C5 (0.716).

The weights of the sub-criteria are sorted with the F-ANP method, according to the defuzzified total relation matrix (Table V).

\section{Results and discussion}

The proposed model was aimed to be practical to use in SMEs in spite of their limited resources. As mentioned before, the model was applied in a SME. As a result of this case study, overall weights of criteria were determined. As it can be seen from Fig. 2, the most important criteria are listed as C41, C43 and C24 respectively; "Senior management in harmony with each other", "Employee requests and demands are collected periodically" and "Pocket reference that includes procedures and fixed rules are available". On the other hand the least important criteria were determined as C51, C32 and C23 respectively; "Data are transformed into real information to make the right decision and stored as enterprise information", "Self-assessment activity are conducted periodically within the scope of corporate evaluation" and "Organizational chart and job descriptions are determined
TABLE V

Defuzzified total relation matrix.

\begin{tabular}{c|c|c|c|c|c|c|c|c|c}
\hline \hline & C1 & C2 & C3 & C4 & C5 & D & R & D+R & D-R \\
\hline C1 & 0.525 & 0.672 & 0.682 & 0.747 & 0.636 & 3.26 & 3.26 & 6.52 & 0.00 \\
C2 & 0.672 & 0.596 & 0.713 & 0.783 & 0.716 & 3.48 & 3.48 & 6.96 & 0.00 \\
C3 & 0.747 & 0.783 & 0.588 & 0.817 & 0.745 & 3.68 & 3.25 & 6.93 & 0.43 \\
C4 & 0.682 & 0.713 & 0.637 & 0.588 & 0.634 & 3.25 & 3.68 & 6.93 & -0.43 \\
C5 & 0.636 & 0.716 & 0.634 & 0.745 & 0.519 & 3.25 & 3.25 & 6.50 & 0.00 \\
\hline
\end{tabular}

*Threshold value: 0.680

and updated". However, this does not state that these criteria are unimportant for the whole business environment. Weights of criteria are specific to the companies and their strategies.

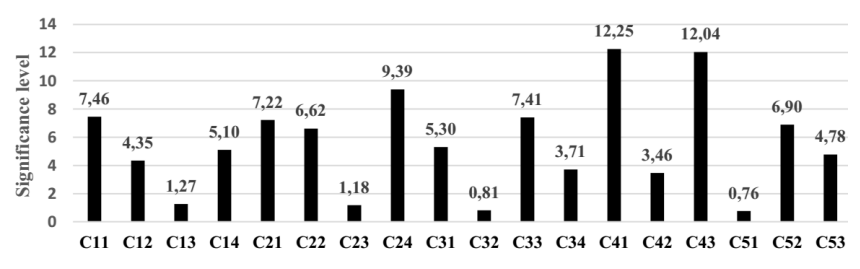

Fig. 2. Sub-criteria weights percentage.

In addition to sub-criteria weights percentage, main criteria weights, which are based on cumulative relevant sub-criteria, are shown in Fig. 3. Corporate communication is the most important criterion for the case company. 
Information and technology management is determined as the least important criterion. This result was expected, since the SMEs operate in medium to low technology environments.

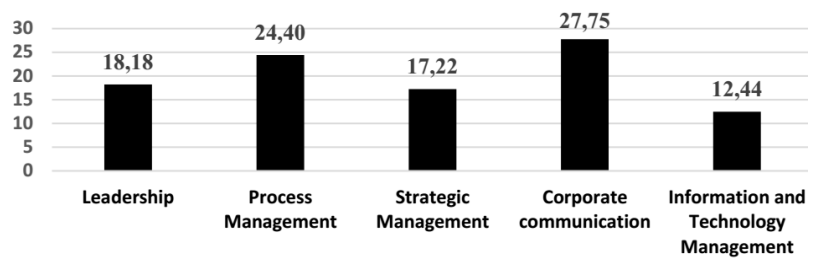

Fig. 3. Criteria weights percentage.

In order to contribute to the literature, this paper presents an evaluation tool, which can be used in manufacturing SMEs. Companies can improve the organization and management performance by giving priority to improvement activities, based on the importance of the performance criteria. This evaluation can be performed at specific time intervals. New criteria can be added to the criteria set or removed from the set.

\section{References}

[1] C.T. Walden, D.Sc Thesis, Mississippi State University, 2007.

[2] D. Chen, S. Thiede, T. Schudeleit, C. Herrmann, CIRP Ann. - Manuf. Technol. 63, 437 (2014).

[3] A. Susilawati, J. Tan, D. Bell, M. Sarwar, Int. J. Lean Think. 4, 51 (2013).

[4] G.K. Kanji, Total Qual. Manag. 13, 715 (2002).

[5] A.H.I. Lee, W.C. Chen, C.J. Chang, Expert Syst. Appl. 34, 96 (2008).

[6] S. Perçin, Manag. Res. Rev. 33, 452 (2010).

[7] G. Büyüközkan, G. Çifçi, Expert Syst. Appl. 39, 3000 (2012).

[8] M. Kabak, M. Dagdeviren, Energy Convers. Manag. 79, 25 (2014).

[9] A. Jaafari, A. Najafi, M.G. Melón, Forest Policy Econ. 50, 200 (2015).

[10] M.B. Erdem, Acta Phys. Pol. A 130, 331 (2016).

[11] B. Tugrul, S. Cimen, Acta Phys. Pol. A 130, 87 (2016).

[12] F.R. Lima-Junior, L.C.R. Carpinetti, Int. J. Prod. Econ. 174, 128 (2016).

[13] R. Chalmeta, S. Palomero, M. Matilla, Int. J. Comput. Integr. Manuf. 25, 716 (2012).

[14] P. Garengo, S. Biazzo, U.S. Bititci, Int. J. Manag. Rev. 7, 25 (2005).

[15] M. Hudson, A. Smart, M. Bourne, Int. J. Oper. Prod. Manag. 21, 1096 (2001).

[16] E.K. Laitinen, G. Chong, Probl. Perspect. Manag. 4, 49 (2006).

[17] S.D. Sousa, E.M. Aspinwall, A.G. Rodrigues, Benchmark.: Int. J. 13, 120 (2006).

[18] T. Canvar Kahveci, D.Sc Thesis, Sakarya University, 2007.
[19] A. Brem, N. Kreusel, C. Neusser, Int. J. Glob. Small Bus. 2, 411 (2008).

[20] A. Ates, P. Garengo, P. Cocca, U.S. Bititci, J. Small Bus. Enterp. Dev. 20, 28 (2013).

[21] K.-F. Pun, Total Qual. Manag. 13, 759 (2002).

[22] H.-K. Chiou, G.-H. Tzeng, D.-C. Cheng, Omega 33, 223 (2005).

[23] J. Wei, R. Bi, in: Proc. Seventh Int. Conf. Mach. Learn. Cybern., Kunming 2008, p. 257.

[24] Y. Huang, J.C. Li, in: 2009 Int. Conf. Inf. Manag. Innov. Manag. Ind. Eng., China 2009, p. 277.

[25] H. Gao, in: 2010 Int. Conf. Logist. Syst. Intell. Manag., 2010, p. 273.

[26] M.-L. Tseng, Comput. Educ. 55, 188 (2010).

[27] B. Mahapatra, K. Mukherjee, C. Bhar, J. Adv. Manag. Sci. 3, 26 (2015).

[28] F.-H. Chen, G.-H. Tzeng, J. Test. Eval. 43, 924 (2015).

[29] Ö. Uygun, T. Canvar Kahveci, H. Taşkin, B. Piriştine, Comput. Ind. Eng. 88, 217 (2015).

[30] M. Zeydan, C. Çolpan, O. Taylan, in: Seventh Int. Conf. Fuzzy Syst. Knowl. Discov., 2010, p. 2959.

[31] L.A. Zadeh, Inf. Control. 8, 338 (1965).

[32] N. Ibadov, Acta Phys. Pol. A 130, 107 (2016).

[33] A. Gabus, E. Fontela, World problems, an invitation to further thought within the framework of DEMATEL, 1972 .

[34] A. Gabus, E. Fontela, Perceptions of the world problematique: Communication procedure, communicating with those bearing collective responsibility, 1973.

[35] E. Fontela, A. Gabus, DEMATEL, innovative methods. Report No. 2 structural analysis of the world problematique, Battelle Geneva Res. Centre, Geneva 1974 , p. 67.

[36] E. Fontela, A. Gabus, The DEMATEL observer DEMATEL 1976 report, 1976.

[37] C.J. Lin, W.W. Wu, Expert Syst. Appl. 34, 205 (2008).

[38] S. Opricovic, G.-H. Tzeng, Int. J. Uncertainty, Fuzziness Knowledge-Based Syst. 11, 635 (2003).

[39] T.L. Saaty, Decision making with dependence and feedback: The analytic network process, RWS Publications, Pittsburgh 1996.

[40] D.-Y. Chang, Eur. J. Oper. Res. 95, 649 (1996).

[41] EFQM Model Kriterleri, www.efqm.org/efqmmodel/model-criteria, accessed December 16, 2014.

[42] The Deming Prize, www.fr-deming.org/Demingprize.html, accessed February 28, 2016.

[43] A. Genaidy, W. Karwowski, Hum. Factors Ergon. Manuf. 16, 61 (2007).

[44] S.K.M. Ho, C.K.H. Fung, Strateg. Chang. 4, 169 (1995).

[45] G.K. Kanji, Total Qual. Manag. 12, 259 (2001). 